\title{
Potential Antioxidative, Anti-inflammatory and Immunomodulatory Effects of Ghrelin, an Endogenous Peptide from the Stomach in SARS-CoV2 Infection
}

\author{
Abbas Jafari ${ }^{1}$ - Sonia Sadeghpour ${ }^{2}$. Hojat Ghasemnejad-Berenji ${ }^{3}$ Sarvin Pashapour ${ }^{4}$ \\ Morteza Ghasemnejad-Berenji ${ }^{5,6}$ (D)
}

Accepted: 10 February 2021 / Published online: 16 April 2021

(c) The Author(s), under exclusive licence to Springer Nature B.V. 2021

\begin{abstract}
The current COVID-19 pandemic is one of the most devastating events in recent history. The respiratory effects of this disease include acute respiratory distress syndrome, systemic inflammation, cytokine storm, and pulmonary fibrosis. Ghrelin, an endogenous ligand for the growth hormone secretagogue receptor, is a peptide hormone secreted mainly by the stomach. Interestingly, ghrelin possesses promising antioxidant, anti-and inflammatory effects, making it an attractive agent to reduce the complications of the SARS-CoV-2. In addition, ghrelin exerts a wide range of immunomodulatory and anti-inflammatory effects and can mitigate the uncontrolled cytokine production responsible for acute lung injury by upregulating PPAR $\gamma$ and down-regulating NF- $\mathrm{KB}$ expression. Ghrelin has also been reported to enhance Nrf2 expression in inflammatory conditions which led to the suppression of oxidative stress. The current opinion summarizes the evidence for the possible pharmacological benefits of ghrelin in the therapeutic management of SARS-CoV-2 infection.
\end{abstract}

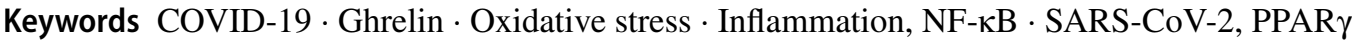

\section{Introduction}

Morteza Ghasemnejad-Berenji

morteza.ghasemnejad@yahoo.com;

ghasemnejad.m@umsu.ac.ir

1 Department of Toxicology and Neurophysiology Research Center, Faculty of Health, Urmia University of Medical Sciences, Urmia, Iran

2 Department of Obstetrics \& Gynecology, School of Medicine, Urmia University of Medical Sciences, Urmia, Iran

3 Department of Anatomy and Reproductive Biology, School of Medicine, Shahid Beheshti University of Medical Sciences, Tehran, Iran

4 Department of Pediatrics, School of Medicine, Urmia University of Medical Sciences, Urmia, Iran

5 Department of Pharmacology and Toxicology, School of Pharmacy, Urmia University of Medical Sciences, PO Box 5715799313, Urmia, Iran

6 Research Center of for Experimental and Applied Pharmaceutical Sciences, Urmia University of Medical Sciences, Urmia, Iran
Coronavirus disease-2019 (COVID-19) is a respiratory infection caused by the severe acute respiratory syndrome coronavirus 2 (SARS-CoV-2), which is a new member of the single-stranded RNA virus of the Coronaviridae family (Ghasemnejad-Berenji and Pashapour 2020a, b; Hosseini et al. 2020). This viral infection can be related to severe lower respiratory symptoms leading to acute respiratory distress syndrome (ARDS), sudden cytokine storm, inflammation, and subsequent death (Girija et al. 2020). It has been reported that ARDS, which is a serious manifestation of COVID-19, is associated with a complex interplay of multiple signaling pathways such as, activation of mitogenactivated protein kinase (MAPKs) and nuclear factor kappalight-chain-enhancer of activated B cells (NF- $\mathrm{kB}$ ) pathway, cytokine storm with sudden inflammation(Allawadhi et al. 2020). Moreover, cases with prior severe chronic lung inflammation like emphysema may suffer from pulmonary fibrosis originated by induction of epithelial-to-mesenchymal transition by fibrogenic growth factors like transforming growth factor-beta (TGF- $\beta$ ) (Gharaee-Kermani et al. 2007). It has been revealed that SARS-CoV-2 inter to the 
host cell through the use of angiotensin-converting enzyme 2 (ACE2) as its cellular receptor. ACE2 is a membrane-bound monocarboxypeptidase found ubiquitously in humans, and expressed predominantly in kidney, heart, intestine and pulmonary alveolar (type II) cells. The entry of SARS$\mathrm{CoV}-2$ into human cells is mediated by the interaction of a receptor-binding domain in its viral spike glycoprotein ectodomain with the ACE2 receptor (Bourgonje et al. 2020). This viral infection can provoke a cytokine storm, whereby pro-inflammatory chemokines and cytokines and such as IL- $1 \beta$, tumor necrosis factor- $\alpha$, and IL- 6 are overproduced by the immune system, resulting in extensive multiorgan injury (Tang et al. 2020). For the management of COVID19 , it is crucial to halt further viral replication as well as provide symptomatic recovery from the systemic complications, especially the respiratory complications (Hassan et al. 2020). Clinically, various antiviral drugs and anti-parasitic drugs have been tried in the past few months. However, the clinically beneficial effects of drugs like, favipiravir (Ghasemnejad-Berenji and Pashapour 2020a, b), hydroxychloroquine, chloroquine and remdesivir have been arguable. Therefore, introducing potential therapeutic targets for COVID-19 can be properly and of greatest importance to ameliorate clinical outcome and reduce mortality (Fakhri et al. 2020; Singh et al. 2020). Ghrelin, a 28-amino-acid acylated peptide produced and secreted predominantly by the X/A-like enteroendocrine cells of the stomach (Fakhri et al. 2020), is a peptide for the growth hormone secretagogue receptor (GHS-R). This endogenous ligand has been shown to possess specific properties that inhibit cell proliferation, oxidative stress, inflammation and, apoptosis (Eid et al. 2018; Prodam and Filigheddu 2014). In this review, we hypothesize that exogenous ghrelin in patients with COVID19 could alleviate some of the severe symptoms that lead to cytokine storm syndrome and ARDS, via modulation of immune responses such as the NF- $\mathrm{KB}$ pathway and a decrease in cytokine production.

\section{Ghrelin Structure and Its Function in the Body}

Ghrelin is a hormone primarily expressed by the X/A-like cells of the stomach. The ghrelin gene encodes a 117 amino acid peptide, known as pre-pro-ghrelin, which is subsequently cleaved into the mature 28 amino acid form in which it is secreted. Therefore, human ghrelin contains 28 amino acids, and a total molecular mass of 3370.9 Dalton and a molecular formula of C149H249N47O42 (Sato et al. 2012). During its maturation in the gastric mucosa and before secretion in the blood, the preproghrelin is first cleaved and part of the proghrelin is octanoylated on its $\mathrm{N}$-terminal 3rd serine residue, in the endoplasmic reticulum lumen. The stomach enzyme involved in ghrelin octanoylation is called ghrelin O-acyltransferase (Gutierrez et al. 2008). Ghrelin-producing cells are not only present on the stomach, but also in the pancreas, duodenum, jejunum, lungs, pancreatic islets, gonads, adrenal cortex, placenta, and kidney. It has also been observed that ghrelin is produced locally in the brain (Ferrini et al. 2009). This hormone could enhance the growth hormone secretion. In addition, ghrelin has been found to be a potent inducer of food intake and also increases adiposity. During states of hunger, acylated ghrelin is released from the stomach into the circulation where it is transported into the brain affecting the feeding centers within the hypothalamus to induce sense of hunger (Delporte 2013). Ghrelin can act in the hypothalamus to regulate food intake, in the hippocampus to regulate neurogenesis, and in the olfactory bulb to regulate food-seeking behaviours. It has been determined that the primary signaling receptor for ghrelin, the growth hormone secretagogue receptor (GHSR), mediates the transport of ghrelin from blood to the brain. Ghrelin has also been reported to influence a number of other biological actions, including effects on glucose homeostasis, reproductive organ functions, sleep, memory, cardiovascular function, hormone secretion, gastrointestinal motility, neurogenesis, pancreatic function, cell proliferation and survival, bone metabolism, gastric emptying, and gastric acid secretion (Dixit and Taub 2005; Stengel and Taché 2012). Furthermore, several studies have demonstrated a role for ghrelin in regulating inflammation and inflammatory cytokine expression in rodents and humans both in vivo and in vitro as well as in T-cell development (Stengel and Taché 2012; Baatar et al. 2011; Dixit et al. 2004; Lin et al. 2016).

\section{Ghrelin and Its Anti-inflammatory Effects}

The anti-inflammatory effects of the endogenous peptides have received much attention in recent years. For example, recently TAT CARMIL1 a combination of two naturally occurring peptides that, when combined, work together to penetrate a cell's membrane in order to dampen an acute inflammatory response. the leucine-rich domains (LRR) of CARMIL1 interacts with IL-1 signaling proteins to facilitate IL-1-mediated matrix degradation. Degradation of the extracellular matrix is fundamental to IL-1-driven inflammatory diseases(Wang et al. 2020a, b, c). Previous studies reported that ghrelin inhibits mononuclear cell binding, proinflammatory cytokine production, and NF- $\mathrm{\kappa B}$ activation in human endothelial cells in vitro, as well as endotoxininduced cytokine production in vivo. This suggests an antiinflammatory function for ghrelin ( $\mathrm{Li}$ et al. 2004; Wu et al. $2007 \mathrm{a}, \mathrm{b})$. There is a lot of evidence that ghrelin plays a key role in regulating immune function and inflammation. Also, ghrelin or its receptor, GHS-R, may have considerable roles 
in various inflammatory disease states (Pereira and Silva 2017). Recently, ghrelin and its specific receptors have been detected in lung tissue, indicating that the peptide may play an important role in respiratory system regulation ( $\mathrm{Li}$ et al. 2015; Zhang et al. 2019). It has been indicated that ghrelin interacted with proinflammatory cytokines and led to systemic inflammation in chronic obstructive pulmonary disease (Itoh et al. 2004; Miki et al. 2012). Ghrelin is also able to decrease basal and tumor necrosis factor $\alpha$ (TNF-a)induced chemotactic cytokine production and mononuclear cell adhesion in human vascular endothelial cells (Hedayati et al. 2009). Furthermore, ghrelin and GHS-R are expressed in human monocytes and T lymphocytes; and activation of GHS-R by this peptide specifically subsides the expression of proinflammatory cytokines such as IL-6, IL-1b, and TNF-a (Dixit et al. 2004). Apart from those 2 cell types, it has been found that ghrelin inhibited endotoxin-induced IL- 6 production and reduced nitrite and nitrate release from peritoneal macrophages in vitro (Abrehdari et al. 2014). In addition, cecal ligation model of sepsis in rats, ghrelin showed an ameliorative effect via NF-kB-dependent pathway (Peng et al. 2012). The downregulation of the brain levels of IL-6 and TNF- $\alpha$ by ghrelin has also been indicated after traumatic brain injury in rats (Qi et al. 2012). Ghrelin also significantly suppressed TNF- $\alpha$ and IL- $1 \beta$ in the infarcted border of cardiac tissue in rats that underwent coronary ligation to induce MI (Yuan et al. 2009). Some examples of published studies and the inflammatory parameters measured after ghrelin administration are shown in Table 1.

\section{Ghrelin and It's Protective Effects Against Acute Lung Injury Models}

Ghrelin and its receptors have been detected in lung tissue, indicating that the peptide may play a role in respiratory regulation. Recent studies indicate that ghrelin has protective effects in acute lung injury models. The biological effects of ghrelin are mediated through the ghrelin receptors in the human lung pulmonary artery wall and parenchyma (Wu et al. 2007a, b; Imazu et al. 2011; Li et al. 2017). According to previous reports, treatment with ghrelin improved morphologic damage, pulmonary parameters, and decreased serum proinflammatory cytokine levels in pancreatitisinduced acute lung injury model. It has been shown that ghrelin could significantly improve the lung architecture in sepsis induced acute lung injury while administration of a specific ghrelin receptor antagonist worsens the survival rate in experimental animals (Zhou and Xue 2010). Furthermore, the ameliorative effect of ghrelin on lipopolysaccharideinduced acute lung inflammation by suppressing the proinflammatory cytokine production in lung macrophages has been observed (Chen et al. 2008).

\section{Clinical Trials on the Use of Ghrelin in Respiratory Inflammatory Disorders}

Despite a plethora of animal studies supporting the therapeutic anti-inflammatory potential of ghrelin, only a few human trials have been conducted on the use of ghrelin in inflammatory disorders. Kodama and colleagues reported that threeweek administration of ghrelin to patients with chronic respiratory infection reduced neutrophil density and air sputum inflammatory cytokine levels, as well as increased exercise tolerance (Kodama et al. 2008). In a randomized doubleblind placebo-controlled trial, three weeks of ghrelin treatment in patients with COPD similarly improved respiratory symptoms and respiratory strength (Miki et al. 2012). More recently, a randomized trial showed ghrelin treatment to reduce inflammation and pulmonary complications during the postoperative period following esophagectomy (Takata et al. 2015).

\section{Preparation of Human Ghrelin and Way of Administration}

In the study of Kodema et al. the synthetic human ghrelin was dissolved in water containing 4\% D-mannitol. This solution was sterilized. The sterilized ghrelin solution was stored in 2-mL vials, each containing $120 \mu \mathrm{g}$ of ghrelin. All vials stored at $-30{ }^{\circ} \mathrm{C}$ until administration. This solution was administered ( $2 \mu \mathrm{g} / \mathrm{kg}, 20 \mathrm{~mL}$ solution) intravenously for 3 weeks to 7 cachectic patients with chronic respiratory infection to confirm ghrelin's effects on airway inflammation (Kodama et al. 2008).

\section{Ghrelin and NF-kB Signaling Pathway}

The NF- $\kappa B$ signaling pathway plays a crucial role in regulating the transcription of cytokine-encoding genes and has been considered a novel promising therapeutic target for inflammatory lung disease (Liu et al. 2017; Park and Christman 2006). Under inactivating conditions, NF- $\mathrm{KB}$ dimers are bound to IKB-inhibitory proteins, which sequester NF- $\kappa B$ in the cytoplasm. Once activated, the IкB kinase complex phosphorylates $\mathrm{I} \kappa \mathrm{B}$ proteins, triggering I $\kappa \mathrm{B}$ ubiquitination and proteasomal degradation, releasing NF- $\mathrm{KB}$ dimers to translocate to the nucleus to induce gene expression (Giridharan and Srinivasan 2018). It has been demonstrated that activation of the NF- $\mathrm{KB}$ pathway plays a significant role in the development of acute lung injury (ALI) during the inflammatory responses (Zhang et al. 2019). The ameliorative effect of exogenous ghrelin 
Table 1 Several examples of ghrelin-mediated regulation of proinflammatory cytokine expression in animal models and humans

\begin{tabular}{|c|c|c|c|}
\hline Cytokine(s) suppressed by ghrelin & Animal/model & Mechanism/target & References \\
\hline TNF- $\alpha$, IL- $1 \beta$ & Mice/acetic acid-induced colitis & NA & Matuszyk et al. (2016) \\
\hline TNF- $\alpha$, IL-6 & $\begin{array}{l}\text { Rats/cecal ligation } \\
\text { sepsis }\end{array}$ & $\begin{array}{l}\text { Activation of vagus } \\
\text { nerve (cholinergic } \\
\text { stimulation) }\end{array}$ & Wu et al. $(2007 a, b)$ \\
\hline IL-8, TNF- CRP, soluble ICAM-1 & $\begin{array}{l}\text { Cachectic patients with chronic res- } \\
\text { piratory infections }\end{array}$ & NA & Kodama et al. (2008) \\
\hline TNF- $\alpha$, IL-6 & Rats/gut ischemia & $\begin{array}{l}\text { Cholinergic } \\
\text { stimulation }\end{array}$ & Wu et al. (2008) \\
\hline TNF- $\alpha$, IL-6 & $\begin{array}{l}\text { Rats/sepsis by cecal ligation and } \\
\text { puncture }\end{array}$ & Stimulation of the vagus nerve & Wu et al. $(2007 a, b)$ \\
\hline $\begin{array}{l}\text { Pooled levels of proinflammatory } \\
\text { cytokines (IL-1 } \beta \text {, TNF- } \alpha \text {, IL-6, } \\
\text { etc.) }\end{array}$ & $\begin{array}{l}\text { Rats/nephrectomy, chronic renal } \\
\text { failure model }\end{array}$ & NA & Wang et al. (2009) \\
\hline IL- $1 \beta, \mathrm{TNF}-\alpha$ & Rats/intratracheal instillation LPS & $\begin{array}{l}\text { Increase in NO } \\
\text { production }\end{array}$ & Chen et al. (2008) \\
\hline TNF- $\alpha$. IL- $1 \beta$ & Rats/cardiac ischemia & Suppression of NF- $\kappa B$ activation & Chang et al. (2004) \\
\hline TNF- $\alpha$, IFN- $\gamma$, IL-6, IL- $1 \alpha$, IL-1 $\beta$ & Mice, colitis & NA & $\begin{array}{l}\text { Wu et al. (2008), Gonza- } \\
\text { lez-Rey et al. (2006) }\end{array}$ \\
\hline TNF- $\alpha$, IL-6 & Rats/burn injury & NA & Şehirli et al. (2008) \\
\hline TNF- $\alpha$, IL- $1 \beta$ & Rat, subarachnoid hemorrhage model & NA & Erşahin et al. (2010) \\
\hline TNF- $\alpha$ & $\begin{array}{l}\text { Rats, acetaminophen induced liver } \\
\text { injury }\end{array}$ & NA & Jahromi et al. (2010) \\
\hline IL-6 & $\begin{array}{l}\text { Dopaminergic SN4741 cell-line } \\
\text { derived from the mouse substantia } \\
\text { nigra }\end{array}$ & NA & Beynon et al. (2013) \\
\hline TNF- $\alpha$ & Balb/c mice/Traumatic brain injury & Vagal Stimulation & Bansal et al. (2012) \\
\hline TNF- $\alpha$, IL-6 & $\begin{array}{l}\text { Rats/high-fat diet for inducing non- } \\
\text { alcoholic fatty liver disease }\end{array}$ & $\begin{array}{l}\text { LKB1/AMPK and PI3 K/Akt path- } \\
\text { ways }\end{array}$ & Li et al. (2013) \\
\hline IL-1 $\beta$, IL-6 & RAW264.7, NHEK cells & $\begin{array}{l}\text { Antagonizing TNF- } \alpha / \mathrm{NF}-\kappa \mathrm{B} \text { signaling } \\
\text { pathways }\end{array}$ & Qu et al. (2019) \\
\hline $\begin{array}{l}\text { TNF- } \alpha, \text { IL- } 1 \beta \text {, and } \\
\text { MCP- } 1\end{array}$ & $\begin{array}{l}\text { Rat/ unilateral ureteral obstruction } \\
\text { model }\end{array}$ & $\begin{array}{l}\text { Suppressing the TGF- } \beta 1 / \mathrm{Smad} 3 / \\
\text { NF- } \mathrm{BB} \text { signaling pathways }\end{array}$ & Sun et al. (2015) \\
\hline L- $1 \beta$, IL- 6, TNF- $\alpha$ and IL-18 & $\begin{array}{l}\text { Mice/ traumatic brain injury-induced } \\
\text { acute lung injury }\end{array}$ & Pyroptosis/NF-кB pathway & Shao et al. (2020) \\
\hline TNF $\alpha$ and IL-6 & Mouse endotoxemia model & NA & Nikitopoulou et al. (2020) \\
\hline
\end{tabular}

$I N F$ Interferon, $I L$ interleukin, $L P S$ lipopolysaccharide, $M C P-1$ monocyte chemoattractant protein-1, $N A$ not analyzed, $N F-\kappa B$ Nuclear factor kappa B, NO nitric oxide, $T N F$ tumor necrosis factor

in sepsis-induced ALI and its effect on reduction of pulmonary levels of proinflammatory cytokines is mediated by preventing NF- $\mathrm{KB}$ activation(Wu et al. 2007a, b; Peng et al. 2012). It has been reported that ghrelin inhibits NF- $\kappa \mathrm{B}$ activity by modulating the expression of an upstream activator, nucleotide-binding oligomerization domain2 (NOD2), which transmits signals to receptor interacting protein (Rip2) to activate NF- $\mathrm{kB}$. Ghrelin has also been reported to down-regulate NF- $\mathrm{KB}$ and TLR-4 expression in ventilator-induced lung injury in rats (Zheng et al. 2019). In a study by Zhang et al. (2019). Furthermore, ghrelin seems to exert anti-inflammatory effects in contact dermatitis and psoriasis by barring activation of the NF- $\mathrm{KB}$ signaling pathway (Qu et al. 2019).

\section{Ghrelin and Immunomodulatory Effect}

Ghrelin, like the expression of several other endogenous gut peptides, is found in immune cells encompassing monocytes and natural killer cells as well as B and T cells (Hattori et al. 2001). In addition, also the ghrelin receptor is expressed on rodent immune cells and has subsequently also been detected on human T cells and monocytes (Hattori 2009). The expression of GH in immune cells is stimulated by ghrelin. This peptide modulates phagocytosis, enhances thymopoiesis and $\mathrm{T}$ cell development, which would be beneficial for patients with immunodeficiency due to glucocorticoid therapy, bone marrow transplantation, and HIV-1 infection. Ghrelin and ghrelin agonists have an immunomodulatory protective 
effect under conditions of acute endotoxemia resulting in reduced tissue infiltration by immune cells and decreased mortality (Kasımay et al. 2006). This could be mediated directly via the interaction with immune cells since ghrelin reduces the mRNA and protein production of the proinflammatory cytokines such as IL- $1 \alpha$, IL- 6 , IL- $1 \beta$, and TNF- $\alpha$ after an immune challenge (Dixit et al. 2004). Ghrelin affects both the Th1 and the Th2 pathways as demonstrated by the suppression of IL- 2 and interferon- $\gamma$ and IL- 4 and IL-10 respectively in mice (Xia et al. 2004). Conversely, when ghrelin expression is knocked down in T cells by silencing RNA, levels of proinflammatory cytokines such as IL-17 and interferon- $\gamma$ were severely increased giving rise to a physiological role of endogenous ghrelin in regulating the inflammatory immune responses (Dixit et al. 2009).

\section{Ghrelin and PPAR- $\boldsymbol{\gamma}$}

Peroxisome proliferator-activated receptor-gamma (PPAR- $\gamma$ ) is a transcription factor belonging to the nuclear hormone receptor superfamily. Various evidence indicates that PPAR- $\gamma$ exerts a broad range of effects on cardiovascular disease and activation of PPAR- $\gamma$ was beneficial to delay the pathological change of fibrosis. Furthermore, PPAR $\gamma$ agonism in resident alveolar macrophages significantly promotes host recovery and limits pulmonary inflammation following respiratory viral infections (Chen et al. 2016; Huang et al. 2019a, b, c). As it has been demonstrated during acute pneumonia, alveolar macrophage largely expresses PPAR $\gamma$ (Huang et al. 2019a, b, c). PPAR $\gamma$ activation is also responsible for the control of cytokine over-production with consequent amelioration of the tissue damage (Esposito et al. 2020). It has been reported that the adipogenic effects of ghrelin are mediated through the activation of PPAR- $\gamma$ (Chabot et al. 2014). Several studies have indicated that ghrelin decreases myocardial fibrosis by upregulating PPAR- $\gamma$ expression (Wang et al. 2018; Zhao et al. 2008).

\section{Ghrelin and Oxidative Stress}

The protective effects of ghrelin on oxidative stress-induced injuries in different organs such as the heart, kidney, brain, lung, gastrointestinal tract, and testis have been reported in several studies (Chang et al. 2004; Imazu et al. 2011; Huang et al. 2019a, b, c; Kheradmand et al. 2009; Suzuki et al. 2010). Ghrelin administration ameliorates experimental paclitaxel-induced neuropathy by increasing mitochondrial number and suppressing mitochondrial reactive oxygen species (ROS) production (Ishii et al. 2018). Studies on the effects of exogenous ghrelin on testicular ischemia have indicated that administration of this peptide increases antioxidant enzyme activities and reduces the lipid peroxidation in the testicular tissue exposed to I/R (Taati et al. 2015, 2016). Furthermore, studies on the effect of ghrelin on cardiopulmonary bypass-induced myocardial injury has shown that ghrelin could exert cardioprotective effects by attenuating oxidative stress (Sukumaran et al. 2018). In addition, it has been reported that ghrelin attenuates sepsis-induced acute lung injury in rats by decreasing pulmonary oxidative stress (Zeng et al. 2015).

\section{Ghreline and Nrf2 Signalling Pathway}

Nuclear factor (erythroid-derived 2)-like 2 (Nrf2) is an important endogenous modulator of ROS over-production by initiating antioxidative defense pathways. The Nrf2 transcription factor is expressed and present in various organs and tissues, including the kidney, muscle, lung, heart, liver, and brain. The Nrf2 transcription factor is tightly regulated by the repressor protein, Keap1 (Kelch-like ECH-associated protein 1). Under oxidative stress conditions, Nrf2 dissociates from Keap1, translocates to the nucleus, and consequently activates several cytoprotective genes to combat oxidative stress (Ma 2013). A recent study on the effects of ghrelin against the secondary brain injury following intracerebral hemorrhage has shown that ghrelin exerts its protective effect by activating the Nrf2 signaling pathway (Jiang et al. 2017). Furthermore, it has been reported that in 1-methyl4-phenyl-1,2,3,6-tetrahydropyridine (MPTP)- Parkinson's disease model, ghrelin markedly enhanced Nrf2 expression which led to the suppression of oxidative stress and protection against MPTP induced cytotoxicity (Wang et al. 2020a, $b, c)$.

\section{Ghrelin and the Potential Beneficial Effects on COVID-19}

ARDS is a predictable severe complication of COVID-19 (Wang et al. 2020a, b, c). It is mediated by a complex interplay of multiple pathways like activation of NFKB pathway, enhanced inflammation, cytokine storm, and oxidative stress (Wang et al. 2020a, b, c; Schönrich et al. 2020; Zhang et al. 2020). Although there is absence of basic, and clinical evidence on therapeutic effects of ghrelin on COVID-19 infection and the associated severe complications, preclinical studies to date demonstrated that this peptide is able to ameliorate the severity of ALI by reducing lung fluid accumulation, hypoxemia and cytokine secretion which occur in COVID-19-associated ARDS (Zheng et al. 2019). In addition to directly causing an improvement in lung dynamics, ghrelin could significantly counteract the onset of the cytokine storm from resident macrophages. 
Therefore, ghrelin may potentially block acute effects of COVID-19, and its beneficial effects may extend to protecting other organs from the cytokine storm and reducing mortality (Yorulmaz et al. 2017). Another possible beneficial effect of ghrelin on COVID-19 could be related to the ability of this peptide on upregulating PPAR- $\gamma$ expression. PPAR- $\gamma$ acts on the transcription of the upstream inflammatory genes, thus preventing the cytokine over-production and becoming an attractive target for immunomodulatory. It has been reported that stimulation of PPAR- $\gamma$ can exert a regulatory role on the cytokine storm induced by viral infections (Wang et al. 2018; Zhao et al. 2008). Reductions in PPAR- $\gamma$ from SARS-CoV-2 may be an important effector of pulmonary inflammation and mechanistically involved in the pathogenesis of acute lung injury (Ciavarella et al. 2020). As such, use of the ghrelin may serve a useful therapeutic role by helping to reverse the inflammatory changes induces by SARS-CoV-2. Viral infections could evoke "cytokine storm" that leads to lung capillary endothelial cell activation, increased oxidative stress, and neutrophil infiltration (Morris et al. 2020). ARDS, characteristic of severe hypoxemia, is usually accompanied by uncontrolled severe inflammation, extensive oxidative injury, and damage to the alveolar-capillary barrier (Meng et al. 2019). Increased oxidative stress is a major insult in pulmonary injury including ALI and ARDS, two clinical manifestations of acute respiratory failure with substantially high morbidity and mortality (Chow et al. 2003). Oxidative stress is the result of an imbalance between oxidant production and antioxidant mechanisms that leads to oxidative damage, including lipid peroxidation and DNA oxidation (Jafari et al. 2020; Yazdani et al. 2019). In addition to the neutrophil infiltration and release of ROS, viral infections are associated with a decrease in antioxidant defenses (Camini et al. 2017). Exposure to pro-oxidants usually leads to nuclear translocation of the master redox-sensitive transcription factor $\mathrm{NRF}_{2}$, which activates antioxidant defenses; however, respiratory viral infections have been associated with inhibition of NRF2mediated pathways and NF- $\mathrm{\kappa B}$ signaling activation, which can promote inflammation and oxidative damage during these infections (Ahmed et al. 2017; Rahman and McFadden 2011; Wardyn et al. 2015). Hence the ameliorative effect of ghrelin on oxidative stress-induced injuries could be the other potential beneficial effect of this peptide on COVID19 (Prodam and Filigheddu 2014; Suzuki et al. 2010; Ercan et al. 2013; Neamati et al. 2011). Several studies have shown that ghrelin could down-regulate NF-KB and upregulate Nrf2 expression in inflammatory states (Zhang et al. 2019; Wang et al. 2020a, b, c; Cheng et al. 2020). Furthermore, a recent study has indicated that Nrf2 activation downregulates ACE2 expression, and its deficiency up-regulates the ACE2 receptor. It has been revealed that Nrf2 knockout mice present an enhancement in ACE2 expression (Zhao et al. 2018). Since ghrelin represses the inflammatory process by reducing oxidative stress and cytokine production; it might play a similar role in protecting against lung injury associated with COVID-19 (Fig. 1).
Fig. 1 The potential of ghrelin in SARS-CoV2 infection. Ghrelin recognizes several receptor targets and displays a multifaceted anti-oxidative, anti-inflammatory and immunomodulatory activity that could limit the severity of SARS-CoV2 infection: ghrelin could down-regulate NF- $\kappa \mathrm{B}$ and upregulate PPAR- $\gamma$ and $\mathrm{Nrf} 2$ expression which lead to repression in cytokine storm and oxidative stress

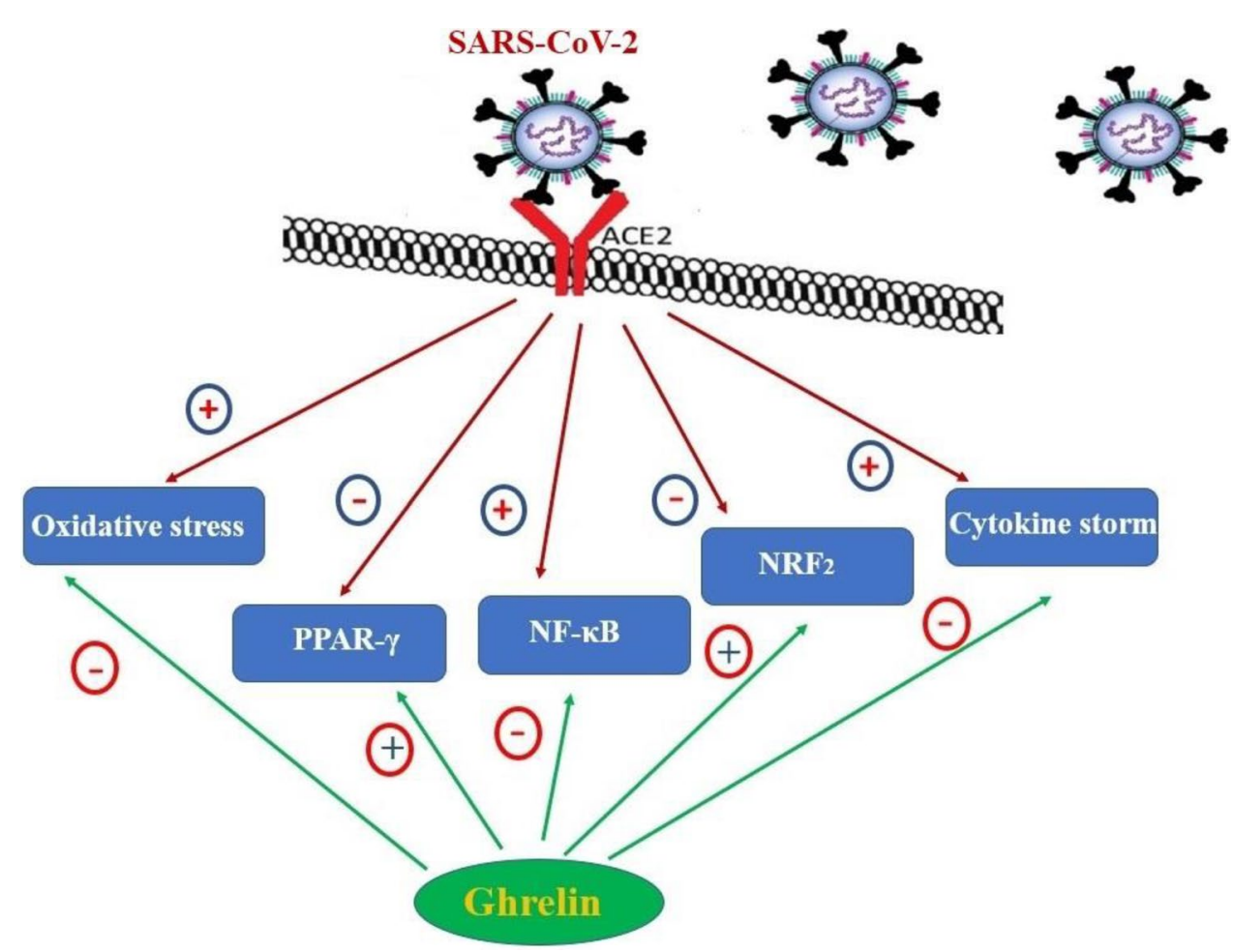




\section{Conclusions}

In conclusion, we suggest that, in parallel to finding compounds for direct blockade of the SARS-CoV-2 penetration, introducing new safe therapeutic strategies for reducing the SARS-CoV-2 induced inflammation and oxidative stress should be paid particular attention. The possible beneficial effects of ghrelin as adjuvant use in COVID-19 in antiinflammation, anti-oxidation, immune response regulation has been repeatedly demonstrated in respiratory disorder models. Herein, based on preclinical evidence, we hypothesize that according to the unique pharmacological properties, ghrelin might be an attractive preclinical candidate to reduce the complications of COVID-19. Further, it may be used as a prevention or treatment strategy in combination with other drugs.

Author Contributions MG-B, SP and AJ: literature review and writing the original draft of the article. SS and HG-B: revised the manuscript. All authors contributed substantially to this work and approved the final manuscript.

Funding No funding.

\section{Declarations}

Conflict of interest The authors declare that there are no conflicts of interest.

Ethical Approval This is a short review article. The Urmia University of Medical Science Research Ethics Committee has confirmed that no ethical approval is required.

\section{References}

Abrehdari $\mathrm{Z}$ et al (2014) The effects of coadministration of ghrelin agonist (GHRP-2) and GH on TNF- $\alpha$, IL-6, and iNOS genes expression induced by LPS in mouse liver. Comp Clin Pathol 23(4):835-840

Ahmed SMU et al (2017) Nrf2 signaling pathway: pivotal roles in inflammation. Biochim Biophys Acta 1863(2):585-597

Allawadhi P et al (2020) Nanoceria as a possible agent for the management of COVID-19. Nano Today 35:100982

Baatar D, Patel K, Taub DD (2011) The effects of ghrelin on inflammation and the immune system. Mol Cell Endocrinol 340(1):44-58

Bansal V et al (2012) Vagal stimulation modulates inflammation through a ghrelin mediated mechanism in traumatic brain injury. Inflammation 35(1):214-220

Beynon AL et al (2013) Ghrelin inhibits LPS-induced release of IL-6 from mouse dopaminergic neurones. J Neuroinflamm 10(1):1-6

Bourgonje AR et al (2020) Angiotensin-converting enzyme-2 (ACE2), SARS-CoV-2 and pathophysiology of coronavirus disease 2019 (COVID-19). J Pathol 251:228

Camini FC et al (2017) Implications of oxidative stress on viral pathogenesis. Arch Virol 162(4):907-917
Chabot $\mathrm{F}$ et al (2014) Interrelationships between ghrelin, insulin and glucose homeostasis: physiological relevance. World J Diabet $5(3): 328$

Chang L et al (2004) Protective effects of ghrelin on ischemia/reperfusion injury in the isolated rat heart. J Cardiovasc Pharmacol 43(2): $165-170$

Chen J et al (2008) Ghrelin attenuates lipopolysaccharide-induced acute lung injury through NO pathway. Med Sci Monit 14(7):BR141-BR146

Chen $M$ et al (2016) Atorvastatin prevents advanced glycation end products (AGEs)-induced cardiac fibrosis via activating peroxisome proliferator-activated receptor gamma (PPAR- $\gamma)$. Metabolism 65(4):441-453

Cheng Y et al (2020) Ghrelin attenuates secondary brain injury following intracerebral hemorrhage by inhibiting NLRP3 inflammasome activation and promoting Nrf2/ARE signaling pathway in mice. Int Immunopharmacol 79:106180

Chow C-W et al (2003) Oxidative stress and acute lung injury. Am J Respir Cell Mol Biol 29(4):427-431

Ciavarella $C$ et al (2020) Pharmacological (or synthetic) and nutritional agonists of PPAR- $\gamma$ as candidates for cytokine storm modulation in COVID-19 disease. Molecules 25(9):2076

Delporte C (2013) Structure and physiological actions of ghrelin. Scientifica 2013:518909

Dixit VD et al (2004) Ghrelin inhibits leptin-and activation-induced proinflammatory cytokine expression by human monocytes and T cells. J Clin Investig 114(1):57-66

Dixit VD, Taub DD (2005) Ghrelin and immunity: a young player in an old field. Exp Gerontol 40(11):900-910

Dixit VD et al (2009) Reduction of T cell-derived ghrelin enhances proinflammatory cytokine expression: implications for ageassociated increases in inflammation. Blood 113(21):5202-5205

Eid RA et al (2018) Acylated ghrelin protects aorta damage post-MI via activation of eNOS and inhibition of angiotensin-converting enzyme induced activation of NAD (P) H-dependent oxidase. Ultrastruct Pathol 42(5):416-429

Ercan S et al (2013) Ghrelin inhibits sodium metabisulfite induced oxidative stress and apoptosis in rat gastric mucosa. Food Chem Toxicol 56:154-161

Erşahin $\mathrm{M}$ et al (2010) The anti-inflammatory and neuroprotective effects of ghrelin in subarachnoid hemorrhage-induced oxidative brain damage in rats. J Neurotrauma 27(6):1143-1155

Esposito G et al (2020) The potential of cannabidiol in the COVID-19 pandemic: a hypothesis letter. Br J Pharm 177:4967

Fakhri S et al (2020) Astaxanthin, COVID-19 and immune response: focus on oxidative stress, apoptosis and autophagy. Phytother Res. https://doi.org/10.1002/ptr.6797

Ferrini F et al (2009) Ghrelin in central neurons. Curr Neuropharmacol 7(1):37-49

Gharaee-Kermani M et al (2007) New insights into the pathogenesis and treatment of idiopathic pulmonary fibrosis: a potential role for stem cells in the lung parenchyma and implications for therapy. Pharm Res 24(5):819-841

Ghasemnejad-Berenji M, Pashapour S (2020) SARS-CoV-2 and the possible role of Raf/MEK/ERK pathway in viral survival: is this a potential therapeutic strategy for COVID-19? Pharmacology 106:119

Ghasemnejad-Berenji M, Pashapour S (2020) Favipiravir and COVID-19: a simplified summary. Drug Res. https://doi.org/10. 1055/a-1296-7935

Giridharan S, Srinivasan M (2018) Mechanisms of NF-кB p65 and strategies for therapeutic manipulation. J Inflamm Res 11:407

Girija A, Shankar EM, Larsson M (2020) Could SARS-CoV-2-induced hyperinflammation magnify the severity of coronavirus disease (CoViD-19) leading to acute respiratory distress syndrome? Front Immunol 11:1206 
Gonzalez-Rey E, Chorny A, Delgado M (2006) Therapeutic action of ghrelin in a mouse model of colitis. Gastroenterology 130(6): 1707-1720

Gutierrez JA et al (2008) Ghrelin octanoylation mediated by an orphan lipid transferase. Proc Natl Acad Sci USA 105(17):6320-6325

Hassan SA et al (2020) Coronavirus (COVID-19): a review of clinical features, diagnosis, and treatment. Cureus 12(3):e7355

Hattori N et al (2001) GH, GH receptor, GH secretagogue receptor, and ghrelin expression in human T cells, B cells, and neutrophils. J Clin Endocrinol Metab 86(9):4284-4291

Hattori N (2009) Expression, regulation and biological actions of growth hormone $(\mathrm{GH})$ and ghrelin in the immune system. Growth Hormon IGF Res 19(3):187-197

Hedayati N et al (2009) Growth hormone-releasing peptide ghrelin inhibits homocysteine-induced endothelial dysfunction in porcine coronary arteries and human endothelial cells. J Vasc Surg 49(1):199-207

Hosseini A et al (2020) Innate and adaptive immune responses against coronavirus. Biomed Pharmacother 132:110859

Huang $S$ et al (2019) Macrophage PPAR- $\gamma$ suppresses long-term lung fibrotic sequelae following acute influenza infection. PLoS ONE 14(10): 0223430

Huang S et al (2019) PPAR- $\gamma$ in macrophages limits pulmonary inflammation and promotes host recovery following respiratory viral infection. J Virol 93:9

Huang J et al (2019) Ghrelin attenuates oxidative stress and neuronal apoptosis via GHSR-1 $\alpha /$ AMPK/Sirt1/PGC- $1 \alpha / \mathrm{UCP} 2$ pathway in a rat model of neonatal HIE. Free Radic Biol Med 141:322-337

Imazu Y et al (2011) Ghrelin ameliorates bleomycin-induced acute lung injury by protecting alveolar epithelial cells and suppressing lung inflammation. Eur J Pharmacol 672(1-3):153-158

Ishii $\mathrm{N}$ et al (2018) Ghrelin alleviates paclitaxel-induced peripheral neuropathy by reducing oxidative stress and enhancing mitochondrial anti-oxidant functions in mice. Eur J Pharmacol 819:35-42

Itoh $\mathrm{T}$ et al (2004) Elevated plasma ghrelin level in underweight patients with chronic obstructive pulmonary disease. Am J Respir Crit Care Med 170(8):879-882

Jafari A et al (2020) Topiramate: a novel protective agent against ischemia reperfusion-induced oxidative injury after testicular torsion/detorsion. Am J Emerg Med. https://doi.org/10.1016/j. ajem.2020.03.060

Jahromi MG et al (2010) Protective effect of ghrelin on acetaminopheninduced liver injury in rat. Peptides 31(11):2114-2117

Jiang L et al (2017) Roles of the Nrf2/HO-1 pathway in the anti-oxidative stress response to ischemia-reperfusion brain injury in rats. Eur Rev Med Pharmacol Sci 21(7):1532-1540

Kasımay Ö et al (2006) Ghrelin ameliorates pancreaticobiliary inflammation and associated remote organ injury in rats. Hepatol Res 36(1):11-19

Kheradmand A et al (2009) Antioxidant enzyme activity and MDA level in the rat testis following chronic administration of ghrelin. Andrologia 41(6):335-340

Kodama T et al (2008) Ghrelin treatment suppresses neutrophil-dominant inflammation in airways of patients with chronic respiratory infection. Pulm Pharmacol Ther 21(5):774-779

Li WG et al (2004) Ghrelin inhibits proinflammatory responses and nuclear factor- $\mathrm{\kappa B}$ activation in human endothelial cells. Circulation 109(18):2221-2226

Li Y et al (2013) Administration of ghrelin improves inflammation, oxidative stress, and apoptosis during and after non-alcoholic fatty liver disease development. Endocrine 43(2):376-386

Li B et al (2015) Ghrelin protects alveolar macrophages against lipopolysaccharide-induced apoptosis through growth hormone secretagogue receptor 1a-dependent c-Jun $\mathrm{N}$-terminal kinase and $\mathrm{Wnt} / \beta$-catenin signaling and suppresses lung inflammation. Endocrinology 156(1):203-217
Li G et al (2017) Protective effects of ghrelin in ventilator-induced lung injury in rats. Int Immunopharmacol 52:85-91

Lin L et al (2016) Ghrelin receptor regulates adipose tissue inflammation in aging. Aging 8(1):178

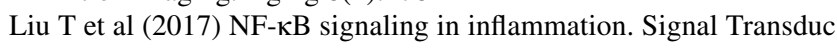
Target therapy 2(1):1-9

Ma Q (2013) Role of nrf2 in oxidative stress and toxicity. Annu Rev Pharmacol Toxicol 53:401-426

Matuszyk A et al (2016) Exogenous ghrelin accelerates the healing of acetic acid-induced colitis in rats. Int J Mol Sci 17(9):1455

Meng L, Zhao X, Zhang H (2019) HIPK1 interference attenuates inflammation and oxidative stress of acute lung injury via autophagy. Med Sci Monitor 25:827

Miki K et al (2012) Ghrelin treatment of cachectic patients with chronic obstructive pulmonary disease: a multicenter, randomized, double-blind, placebo-controlled trial. PLoS ONE 7(5):e35708

Morris G et al (2020) The pathophysiology of SARS-CoV-2: a suggested model and therapeutic approach. Life Sci 258:118166

Neamati S, Alirezaei M, Kheradmand A (2011) Ghrelin acts as an antioxidant agent in the rat kidney. Int J Pept Res Ther 17(3):239

Nikitopoulou I et al (2020) Ghrelin alterations during experimental and human sepsis. Cytokine 127:154937

Park GY, Christman JW (2006) Nuclear factor kappa B is a promising therapeutic target in inflammatory lung disease. Curr Drug Targets 7(6):661-668

Peng Z et al (2012) Effects of ghrelin on pulmonary NOD2 mRNA expression and NF- $\kappa \mathrm{B}$ activation when protects against acute lung injury in rats challenged with cecal ligation and puncture. Int Immunopharmacol 13(4):440-445

Pereira JADS, Silva FCD, de Moraes-Vieira PMM (2017) The impact of ghrelin in metabolic diseases: an immune perspective. J Diabet Res 2017:4527980

Prodam F, Filigheddu N (2014) Ghrelin gene products in acute and chronic inflammation. Arch Immunol Ther Exp 62(5):369-384

Qi L et al (2012) Ghrelin attenuates brain injury after traumatic brain injury and uncontrolled hemorrhagic shock in rats. Mol Med 18(2):186-193

$\mathrm{Qu} R$ et al (2019) Ghrelin protects against contact dermatitis and psoriasiform skin inflammation by antagonizing TNF- $\alpha / \mathrm{NF}-\kappa \mathrm{B}$ signaling pathways. Sci Rep 9(1):1-14

Rahman MM, McFadden G (2011) Modulation of NF- $\kappa B$ signalling by microbial pathogens. Nat Rev Microbiol 9(4):291-306

Sato T et al (2012) Structure, regulation and function of ghrelin. J Biochem 151(2):119-128

Schönrich G, Raftery MJ, Samstag Y (2020) Devilishly radical NETwork in COVID-19: oxidative stress, neutrophil extracellular traps (NETs), and T cell suppression. Adv Biol Regulat 77:100741

Şehirli Ö et al (2008) Ghrelin improves burn-induced multiple organ injury by depressing neutrophil infiltration and the release of pro-inflammatory cytokines. Peptides 29(7):1231-1240

Shao X-F et al (2020) Ghrelin alleviates traumatic brain injury-induced acute lung injury through pyroptosis/NF-кB pathway. Int Immunopharmacol 79:106175

Singh TU et al (2020) Drug repurposing approach to fight COVID-19. Pharmacol Rep. https://doi.org/10.1007/s43440-020-00155-6

Stengel A, Taché Y (2012) Ghrelin: a pleiotropic hormone secreted from endocrine X/A-like cells of the stomach. Front Neuro Sci $6: 24$

Sukumaran V et al (2018) Ghrelin pre-treatment attenuates local oxidative stress and end organ damage during cardiopulmonary bypass in anesthetized rats. Front Physiol 9:196

Sun G-X et al (2015) Ghrelin attenuates renal fibrosis and inflammation of obstructive nephropathy. J Urol 193(6):2107-2115

Suzuki H, Matsuzaki J, Hibi T (2010) Ghrelin and oxidative stress in gastrointestinal tract. J Clin Biochem Nutr 28:122 
Taati M et al (2015) Effects of Ghrelin on germ cell apoptosis and proinflammatory cytokines production in Ischemia-reperfusion of the rat testis. Iran J Reprod Med 13(2):85

Taati M et al (2016) Effects of ghrelin on testicular ischemia/reperfusion-induced injury. Acta Med Iran 54:32-38

Takata A et al (2015) Randomized phase II study of the anti-inflammatory effect of ghrelin during the postoperative period of esophagectomy. Ann Surg 262(2):230-236

Tang Y et al (2020) Cytokine storm in COVID-19: the current evidence and treatment strategies. Front Immunol 11:1708

Wang W et al (2009) Ghrelin protects mice against endotoxemiainduced acute kidney injury. Am J Physiol 297(4):F1032-F1037

Wang Q et al (2018) Ghrelin ameliorates angiotensin II-induced myocardial fibrosis by upregulating peroxisome proliferatoractivated receptor gamma in Young male rats. BioMed Res Int 2018:9897581

Wang Q et al (2020) The leucine-rich repeat region of CARMIL1 regulates IL-1-mediated ERK activation, MMP expression, and collagen degradation. Cell Rep 31(13):107781

Wang H et al (2020) Ghrelin mitigates MPP+-induced cytotoxicity: involvement of ERK1/2-mediated Nrf2/HO-1 and endoplasmic reticulum stress PERK signaling pathway. Peptides 133:170374

Wang $\mathbf{J}$ et al (2020) Tissue plasminogen activator (tPA) treatment for COVID-19 associated acute respiratory distress syndrome (ARDS): a case series. J Thromb Haemost 18:1752

Wardyn JD, Ponsford AH, Sanderson CM (2015) Dissecting molecular cross-talk between Nrf2 and NF- $\mathrm{kB}$ response pathways. Biochem Soc Trans 43(4):621-626

$\mathrm{Wu} \mathrm{R}$ et al (2007a) Ghrelin attenuates sepsis-induced acute lung injury and mortality in rats. Am J Respir Crit Care Med 176(8):805-813

Wu R et al (2007) Ghrelin down-regulates proinflammatory cytokines in sepsis through activation of the vagus nerve. Ann Surg 245(3):480

Wu R et al (2008) Orexigenic hormone ghrelin attenuates local and remote organ injury after intestinal ischemia-reperfusion. PLoS ONE 3(4):e2026

Xia Q et al (2004) Effects of ghrelin on the proliferation and secretion of splenic T lymphocytes in mice. Regulatory Peptides 122(3):173-178
Yazdani I et al (2019) Comparison of multiple doses of cyclosporine A on germ cell apoptosis and epididymal sperm parameters after testicular ischemia/reperfusion in rats. Exp Mol Pathol 110:104271

Yorulmaz H et al (2017) Investigation of the effectiveness of ghrelin treatment in lung tissue of rats with sepsis. Bratisl Lek Listy 118:858

Yuan M-J et al (2009) A novel peptide ghrelin inhibits neural remodeling after myocardial infarction in rats. Eur $\mathrm{J}$ Pharmacol 618(1-3):52-57

Zeng M et al (2015) Ghrelin attenuates sepsis-associated acute lung injury oxidative stress in rats. Inflammation 38(2):683-690

Zhang L-N et al (2019) Exogenous ghrelin ameliorates acute lung injury by modulating the nuclear factor $\mathrm{\kappa B}$ inhibitor kinase/ nuclear factor $\kappa \mathrm{B}$ inhibitor/nuclear factor $\mathrm{\kappa B}$ pathway after hemorrhagic shock. Int Immunopharmacol 69:95-102

Zhang R et al (2020) COVID-19: melatonin as a potential adjuvant treatment. Life Sci 250:117583

Zhao L et al (2008) Protective effect of ghrelin on left ventricular remodeling in spontaneously hypertensive rats is associated with the peroxisome proliferator-activated receptor gamma-dependent pathway. Chin Med J 121(22):2299-2304

Zhao S et al (2018) Nrf2 deficiency upregulates intrarenal angiotensinconverting enzyme- 2 and angiotensin 1-7 receptor expression and attenuates hypertension and nephropathy in diabetic mice. Endocrinology 159(2):836-852

Zheng $\mathrm{H}$ et al (2019) Ghrelin attenuates sepsis-induced acute lung injury by inhibiting the NF- $\mathrm{KB}$, iNOS, and Akt signaling in alveolar macrophages. Am J Physiol 317(3):L381-L391

Zhou X, Xue C (2010) Ghrelin attenuates acute pancreatitis-induced lung injury and inhibits substance P expression. Am J Med Sci 339(1):49-54

Publisher's note Springer Nature remains neutral with regard to jurisdictional claims in published maps and institutional affiliations. 